\title{
A Fractal Approach for Predicting Unsaturated Hydraulic Conductivity of Deformable Clay
}

\author{
Gaoliang Tao, ${ }^{1}$ Xueliang Zhu, ${ }^{1}$ Jianchao Cai ${ }^{D},{ }^{2}$ Henglin Xiao ${ }^{D},{ }^{1}$ Qingsheng Chen, \\ and Yin Chen ${ }^{1}$ \\ ${ }^{1}$ Hubei Provincial Ecological Road Engineering Technology Research Center, Hubei University of Technology, Wuhan 430068, China \\ ${ }^{2}$ Institute of Geophysics and Geomatics, China University of Geosciences, Wuhan 430074, China \\ Correspondence should be addressed to Jianchao Cai; caijc@cug.edu.cn and Henglin Xiao; xiao-henglin@163.com
}

Received 18 December 2018; Revised 30 January 2019; Accepted 7 March 2019; Published 2 May 2019

Guest Editor: Fengshou Zhang

Copyright (C) 2019 Gaoliang Tao et al. This is an open access article distributed under the Creative Commons Attribution License, which permits unrestricted use, distribution, and reproduction in any medium, provided the original work is properly cited.

\begin{abstract}
The relative hydraulic conductivity is one of the key parameters for unsaturated soils in numerous fields of geotechnical engineering. The quantitative description of its variation law is of significant theoretical and technical values. Parameters in a classical hydraulic conductivity model are generally complex; it is difficult to apply these parameters to predict and estimate the relative hydraulic conductivity under deformation condition. Based on the fractal theory, a simple method is presented in this study for predicting the relative hydraulic conductivity under deformation condition. From the experimental soil-water characteristic curve at a reference state, the fractal dimension and air-entry value are determined at a reference state. By using the prediction model of air-entry value, the air-entry values at the deformed state are then determined. With the two parameters determined, the relative hydraulic conductivity at the deformed state is predicted using the fractal model of relative hydraulic conductivity. The unsaturated hydraulic conductivity of deformable Hunan clay is measured by the instantaneous profile method. Values of relative hydraulic conductivity predicted by the fractal model are compared with those obtained from experimental measurements, which proves the rationality of the proposed prediction method.
\end{abstract}

\section{Introduction}

The seepage analysis of unsaturated soils is one of the hot topics in geotechnical and geoenvironmental engineering. There are many phenomena related to seepage problem, such as slope landslide disasters caused by rainfalls, antiseepage of the earth dikes, and transport of pollutants in underground soils. The unsaturated hydraulic conductivity is the most critical parameter in seepage analysis [1], which can be directly measured in laboratory experiments, e.g., steadystate test [2-4], instantaneous profile test, and other tests [5-7]. However, the direct methods are not only complex, time consuming, and labor intensive but also the accuracy and operability of test instrument require improvement. These problems have motivated many researchers to study the prediction method of hydraulic unsaturated conductivity. In addition, the seepage analysis of unsaturated soil under complex conditions relies on the prediction method of hydraulic conductivity [8]. Therefore, it is of great significance to preciously predict and estimate the unsaturated hydraulic conductivity $[9,10]$.

Mualem and Klute [11] provided a detailed overview of various models for hydraulic conductivity and divided the prediction model of hydraulic conductivity into three species: empirical forms, macroscopic models, and statistical models. The empirical forms and macroscopic models describe the relationship between unsaturated hydraulic conductivity and matric suction (or volumetric water content) through mathematical simple functions [12-16]. The statistical models are indirect methods for predicting unsaturated hydraulic conductivity from the soil-water characteristic curve (SWCC). Fredlund et al. [17] established a method for predicting unsaturated hydraulic conductivity through a complicated calculation procedure. The calculation procedure is done as follows: the SWCC was divided into $m$ stage along the direction of volumetric water content, 
each stage of hydraulic conductivity was calculated by the matric suction at the middle point of each stage, and the accumulative calculation was carried out for obtaining unsaturated hydraulic conductivity. Based on the previous achievements in seepage analysis field, Agus et al. [18] evaluated and summarized four statistical models, i.e., the CCG model [19], modified CCG model [20], Burdine model [21], and Mualem model [22]. Although these models commendably describe the variation of hydraulic conductivity for different soils, the applicability of these models is still principally limited due to its complexity to some extent [23-26].

On the other hand, some researchers have devoted to improving these classical statistical models for more convenient and simple methods. Since Mandelbrot and Wheeler [27] proposed the concept of fractal geometry, the fractal theory has been widely used in the analysis of physical geometry properties as a mathematical method [28-31]. The fractal theory relates the unsaturated hydraulic conductivity to characterization of soil structure $[32,33]$, which provides a powerful tool to indirectly predict the hydraulic conductivity. Compared with the method of sectional calculation and integral calculation proposed by Fredlund et al. [17] and Agus et al. [18], the fractal model can simplify the complicated calculation procedure about relative hydraulic conductivity. Tyler and Wheatcraft [34] derived the fractal model of relative hydraulic conductivity based on a fractal model of SWCC. Based on the fractal theory, many researchers have derived new models for estimating the relative hydraulic conductivity, but the influence of deformation on hydraulic conductivity was not considered [35-43].

Many efforts have been done to examine the unsaturated hydraulic conductivity under deformation condition. Lloret and Alonso [44] investigated the effect of the void ratios and saturation separately on the unsaturated hydraulic conductivity and put forward the method of relative unsaturated hydraulic conductivity under deformation condition. Huang et al. $[45,46]$ proposed and verified an innovative method of hydraulic conductivity of unsaturated soil under deformation condition. Wang et al. [47] researched the variation of unsaturated hydraulic conductivity with volumetric water content and dry density. Assouline [48] proposed a model to predict the influence of soil density on hydraulic conductivity. Hu et al. [49] investigated a model taking into account the variation of pore size distribution, which predicted the relative hydraulic conductivity under deformation condition combined with the Mualem model. Cai et al. [50] presented an indirect prediction approach for the relative hydraulic conductivity taking account of the effect of initial void ratios. Fortunately, based on the fractal theory, Zhou et al. [51] proposed the unsaturated hydraulic conductivity model considering the effect of porosity. In this method, two fractal dimensions were used to describe the fractal characteristics of pore structure. The change law of maximum pore size with porosity was predicted from the existing empirical model; then, the air-entry value can be predicted. Eventually, based on the Mualem model, Zhou et al. [51] derived a fractal model of relative hydraulic conductivity considering the effect of porosity.
Tao and Kong [52] derived a new theoretical model from microscopic pore channels to predict the relative hydraulic conductivity. However, the predicted relative hydraulic conductivity is in a scatter plot, which is uncontinuous and hard to meet the requirement of unsaturated seepage analysis. Moreover, the calculation programs of prediction methods are complex and inconvenient for engineering application. Therefore, it can be seen that a new simple method is further expected to predict the relative hydraulic conductivity under deformation condition. According to the fractal theory, the predicted method of SWCC taking into account the influence of initial void ratio was proposed by Tao et al. [53]. On this basis, a predicted method of relative hydraulic conductivity under deformation condition was presented in this paper combined with the fractal model of relative hydraulic conductivity. This method is able to obtain the continuous curve of relative hydraulic conductivity under different matric suction conditions, which satisfy the theoretical research on seepage analysis. Furthermore, it is simple and convenient for practical engineering application. It is worth noting that the model presented in this paper is different from that proposed by Zhou et al. [51]. In this paper, only one fractal dimension is used to describe the pore distribution characteristics, the air-entry value is directly predicted by the air-entry value model proposed by Tao et al. [53], and a fractal model of relative hydraulic conductivity is derived by using the Tao-Kong model (Tao et al. [54] indicated that the Tao-Kong model yields good predictions against measured data when the fractal dimension is large, while the predictions of the Mualem model agree well with the measured results of the relative hydraulic conductivity when the fractal dimension is relatively small). In contrast with the proposed model in this paper, the computational efforts of Zhou et al. [51] are relatively complex.

In addition, due to the experimental difficulty and long experimental period, little experimental data is reported to verify the existing models considering the effect of different initial void ratios. Thus, it is particularly urgent to supplement relevant experiments. In this paper, the unsaturated hydraulic conductivity of deformable Hunan clay is measured by the instantaneous profile method to verify the proposed model. The instantaneous profile method took more than a year; consequently, the experimental data obtained in this study will be a useful supplement in the hydraulic field for unsaturated soils. The good agreement between the predicted values of the relative hydraulic conductivity and experimental data demonstrates that the proposed model efficiently captures the effects of deformation condition on the hydraulic conductivity.

\section{Basic Theory}

2.1. Hydraulic Conductivity Model. According to the channels of microscopic pore, a saturated hydraulic conductivity model can be expressed as [52]

$$
k_{s}=\frac{\gamma T_{s}^{2} \cos ^{2} \alpha}{2 p_{i} \eta} \int_{\theta_{r}}^{\theta_{s}} \frac{d \theta}{\psi^{2}(\theta)},
$$


where $k_{s}$ is the saturated hydraulic conductivity, $\gamma$ is the bulk density, $T_{s}$ is the surface tension, $\alpha$ is the contact angle, $\eta$ is the viscosity, $p_{i}$ is the ratios of the actual length of the micropore channel in the class $i$ to the soil sample length, $\theta$ is the volumetric water content $\left(\theta_{r}\right.$ and $\theta_{s}$ are the residual volumetric and saturated volumetric water content, respectively), and $\psi$ is the matric suction.

On this basis, the unsaturated hydraulic conductivity $k_{w}$ can be obtained:

$$
k_{w}=\frac{\gamma T_{s}^{2} \cos ^{2} \alpha}{2 p_{i} \eta} \int_{\theta_{r}}^{\theta} \frac{d \theta}{\psi^{2}(\theta)} .
$$

Dividing equation (2) by equation (1), the calculus form of the relative hydraulic conductivity be described as

$$
k_{r}(\theta)=\frac{\int_{\theta_{r}}^{\theta}\left(d \theta /\left(\psi^{2}(\theta)\right)\right)}{\int_{\theta_{r}}^{\theta_{s}}\left(d \theta /\left(\psi^{2}(\theta)\right)\right)},
$$

where $k_{r}$ is the relative hydraulic conductivity, which is defined as the ratio between the unsaturated hydraulic conductivity and its corresponding saturated hydraulic conductivity $\left(k_{w} / k_{s}\right)$.

2.2. Fractal Form of Hydraulic Conductivity Model. As presented by Tao et al. [53], a SWCC fractal model can be proposed; it is expressed as follows:

$$
\left\{\begin{array}{l}
w=w_{s}\left(\frac{\psi_{a}}{\psi}\right)^{3-D}, \quad \psi \geq \psi_{a}, \\
w=w_{s}, \quad \psi<\psi_{a},
\end{array}\right.
$$

where $w$ is gravimetric water content $\left(w_{s}\right.$ is saturated gravimetric water content), $D$ is the fractal dimension, and $\psi_{a}$ is the air-entry value.

The fractal model of SWCC is derived by the gravimetric water content. According to the relationship between the gravimetric and volumetric water content, it is also applicable to volumetric water content through the conversion equation:

$$
\theta=\frac{w \cdot G_{s}}{1+e}
$$

where $e$ is the initial void ratio and $G_{s}$ is the relative particle density.

Then, substituting equation (5) into equation (4), the volumetric water content of fractal characteristics can be obtained:

$$
\left\{\begin{array}{l}
\theta=\theta_{s}\left(\frac{\psi_{a}}{\psi}\right)^{3-D}, \quad \psi \geq \psi_{a} \\
\theta=\theta_{s}, \quad \psi<\psi_{a} .
\end{array}\right.
$$

The differential form of equation (6) is expressed as

$$
d \theta=(D-3) \theta_{s} \psi_{a}^{3-D} \psi^{D-4} d \psi
$$

Equation (7) is differential expression of equation (6) at $\psi \geq \psi_{a}$; accordingly, the application range of equation (7) is $\psi \geq \psi_{a}$. Then, substituting equation (7) into equation (3), the following expression is yielded:

$$
\begin{aligned}
k_{r}(\theta) & =\frac{\int_{\theta_{r}}^{\theta}\left(d \theta /\left(\psi^{2}(\theta)\right)\right)}{\int_{\theta_{r}}^{\theta_{s}}\left(d \theta /\left(\psi^{2}(\theta)\right)\right)} \\
& =\frac{\theta_{s}(D-3) \psi_{a}^{3-D} \int_{\psi_{d}}^{\psi} \psi^{D-6} d \psi}{\theta_{s}(D-3) \psi_{a}^{3-D} \int_{\psi_{d}}^{\psi_{a}} \psi^{D-6} d \psi}=\frac{\int_{\psi_{d}}^{\psi} \psi^{D-6} d \psi}{\int_{\psi_{d}}^{\psi_{a}} \psi^{D-6} d \psi} \\
& =\frac{\left(\psi^{D-5}-\psi_{d}^{D-5}\right)}{\left(\psi_{a}^{D-5}-\psi_{d}^{D-5}\right)}=\frac{\left(\psi / \psi_{a}\right)^{D-5}-\left(\psi_{d} / \psi_{a}\right)^{D-5}}{1-\left(\psi_{d} / \psi_{a}\right)^{D-5}},
\end{aligned}
$$

where $\psi_{d}$ is the matric suction corresponding to residual volumetric water content $\left(\theta_{r}\right)$. Since $D<3$ and $\psi_{a} \ll \psi_{d}$, $\left(\psi_{d} / \psi_{a}\right)^{D-5}$, is approaching infinitesimal, so Equation (8) is simplified as

$$
k_{r}(\psi)=\left(\frac{\psi_{a}}{\psi}\right)^{5-D}
$$

It is noted that equation (9) is applicable to the stage when the matric suction is greater than the air-entry value $\left(\psi \geq \psi_{a}\right)$, while the $k_{r}$ value is taken as one when the matric suction is less than the air-entry value $\left(\psi<\psi_{a}\right)$. The continuous curve of the relative hydraulic conductivity can be obtained by the fractal form of the hydraulic conductivity model, which is simple and convenient for practical engineering application.

2.3. Estimation of Unsaturated Hydraulic Conductivity. The main purpose of this paper is to predict the relative hydraulic conductivity under deformation condition. It is found from equation (9) that the unsaturated relative hydraulic conductivity is mainly controlled by the fractal dimension and the air-entry value, and it can also be applied to the prediction of relative hydraulic conductivity under deformation condition.

The process of determining the fractal dimension and the air-entry value is described as follows.

By taking the logarithm of both sides of equation (6), there is

$$
\ln \theta=(3-D)(-\ln \psi)+\ln \left[\theta_{s} \cdot \psi_{a}^{(3-D)}\right]
$$

Then, it is easy to obtain

$$
\ln \theta \propto(3-D)(-\ln \psi)
$$

The fractal dimension is obtained by fitting experimental SWCC to equation (11). According to Tao et al. [55], the matric suction corresponding to the maximum pore size 
$\left(r_{\max }\right)$ is defined as the air-entry value $\left(\psi_{a}\right)$. Meanwhile, the fractal model of pore volume should be satisfied with $r \leq r_{\max }$. On the basis of the Young-Laplace equation, $\psi$ is inversely proportional to $r$. So for a better fitting effect, it is better to adopt the experimental data at the stage of $\psi \geq \psi_{a}$. By plotting the $\ln \theta$ against $-\ln \psi$, the fractal dimension can be calculated by $D=3-k$, in which $k$ is the gradient of the graph. Note that the fractal dimension is seen as a constant for the same soil with different initial void ratios [53].

Following Tao et al. [53], the air-entry value at different initial void ratios can be determined as

$$
\psi_{a i}=\frac{\psi_{a 0}}{\left(e_{i} / e_{0}\right)^{1 /\left(3-D_{0}\right)}},
$$

where $\psi_{a 0}$ is the air-entry value of a maximum initial void ratio $\left(e_{0}\right), \psi_{a i}$ is the air-entry value of a random initial void ratio $e_{i}\left(e_{i}<e_{0}\right)$, and $D_{0}$ is the fractal dimension of a maximum initial void ratio $\left(e_{0}\right)$.

It is worth pointing that the maximum initial void ratio $\left(e_{0}\right)$ refers to the reference state of soil sample, while the random initial void ratio $e_{i}\left(e_{i}<e_{0}\right)$ is corresponding to the deformed state of soil samples. Therefore, the same soil with different initial void ratios is taken as a different type of deformation condition.

By using equation (12), the air-entry value of random initial void ratios $\left(e_{i}\right)$ is determined. After determination of the fractal dimension and air-entry value, the unsaturated relative hydraulic conductivity with different initial void ratios can be predicted from equation (9).

2.4. Hydraulic Experiments of Deformable Hunan Clay. The soil samples in this study are unsaturated clay soils in Hunan Province with a liquid limit of $46.34 \%$, a plastic limit of $27.84 \%$, and a relative particle density of 2.76 . For the preparation of the soil sample, firstly, the soil was air-dried naturally until no obvious changes in gravimetric water content were measured, and that soil should be crushed and passed through the $2 \mathrm{~mm}$ standard sieve later. Soils were then mixed with a certain water quantity to reach the objective initial gravimetric water content about $19 \%$. Importantly, the mixture should be placed in the hermetic box for at least 48 hours to make sure of the migration of water in soil, and then, the gravimetric water content was measured again.

Two sets of soil samples at five different initial void ratios $(1.12,1.04,0.97,0.90$, and 0.84$)$ were prepared by hydraulic jack. After vacuum and saturation, one set of samples was used to the SWCC test, and another set of samples was used in the variable water head test for measuring the saturated hydraulic conductivity. In the experimental process, the gravimetric water content was measured. But for calculation and model verification, the gravimetric water content should be converted into the volumetric water content by using equation (5).

2.5. Soil-Water Characteristic Curve Test. The pressure plate instrument produced by the Soil Moisture Company of the USA was selected for the SWCC test. The tests were executed

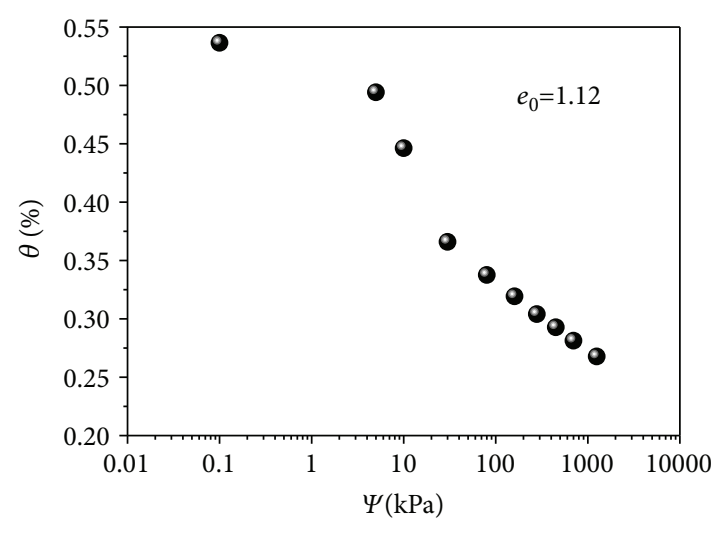

- Experimental data

Figure 1: Measured SWCC for Hunan clay $\left(e_{0}=1.12\right)$.

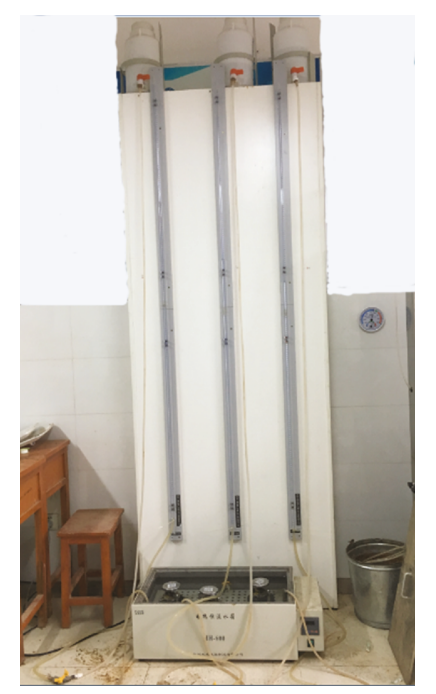

Figure 2: Saturated permeability test.

by increasing gradually the matric suction from 0 to $1250 \mathrm{kPa}$ $(0,5,10,30,80,280,280,450,700$, and $1250 \mathrm{kPa})$ without net stress. When the pore water was allowed to drain from the soil sample in pursuit of equilibrium in each level, the volumetric water content corresponding to specified matric suction was calculated from the amount of drainage in the soil sample. The experimental SWCC at the reference state $\left(e_{0}=1.12\right)$ of Hunan clay is shown in Figure 1.

\subsection{Permeability Test}

2.6.1. Saturated Permeability Test. The saturated hydraulic conductivity of Hunan clay with different initial void ratios was measured by the variable water head test; the equipment of testing was TST-55 Permeameter (Figure 2). Then, multiple tests were performed to obtain the average value for high accuracy. The saturated hydraulic conductivity of soil samples with different initial void ratios at $20^{\circ} \mathrm{C}$ was obtained by temperature modification as shown in Table 1 .

2.6.2. Unsaturated Permeability Test. The instantaneous profile method was employed to measure the unsaturated 
TABLE 1: Measured values of saturated hydraulic conductivity of Hunan clay.

\begin{tabular}{lccccc}
\hline$e$ & 1.12 & 1.04 & 0.97 & 0.90 & 0.84 \\
$k_{s}(\mathrm{~cm} / \mathrm{s})$ & $7.72 \times 10^{-4}$ & $4.15 \times 10^{-4}$ & $2.49 \times 10^{-4}$ & $1.73 \times 10^{-4}$ & $7.63 \times 10^{-5}$ \\
\hline
\end{tabular}

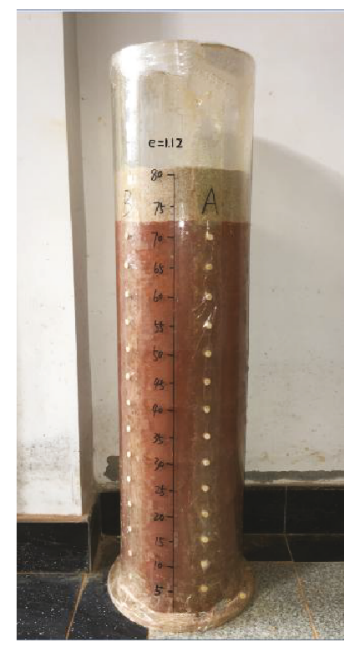

FIgURE 3: Unsaturated permeability test.

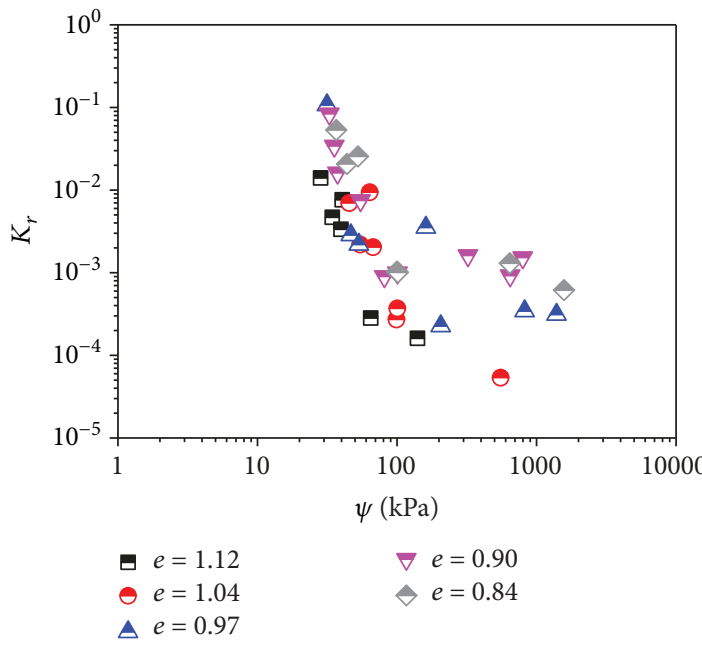

FIGURE 4: Measurement of the relative hydraulic conductivity of deformable Hunan clay.

hydraulic conductivity of deformable Hunan clay. The equipment of the instantaneous profile method was a special type of glass cylinder with a height of $1 \mathrm{~m}$ and a diameter of $25 \mathrm{~cm}$, which was designed by ourselves. At the side of the glass cylinder, 5 columns of holes were arranged uniformly, and each column of holes was evenly distributed with a vertical interval of $5 \mathrm{~cm}$ (Figure 3). But, these holes were sealed when the test was starting. Under the action of gravity and capillary force, the water flow permeated into the bottom of the cylinder, which accelerated the test process. The water flow accorded with the requirement of one-dimensional seepage condition and Darcy's law.

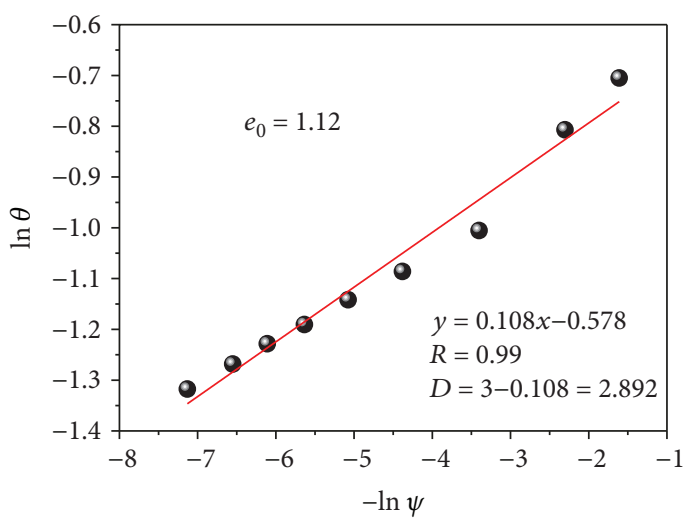

- Experimental data Fitting analysis

Figure 5: Fractal dimension of Hunan clay.

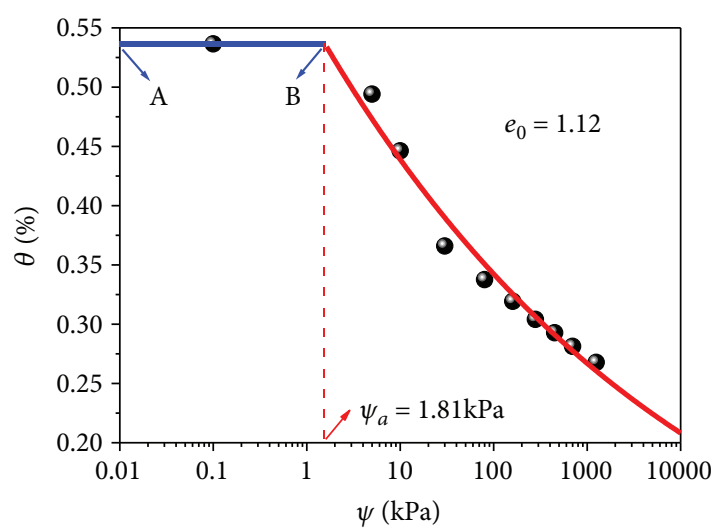

- Experimental data - Fitting curve

FIgURE 6: SWCC fitting to get the air-entry value at a reference state $\left(e_{0}=1.12\right)$.

TABle 2: Predicted and experimental result of air-entry value.

\begin{tabular}{lcc}
\hline \multirow{2}{*}{ Initial void ratios } & \multicolumn{2}{c}{ Air-entry value $(\mathrm{kPa})$} \\
& Experimental results & Predicted values \\
\hline 1.12 & 1.81 & 1.81 \\
1.04 & 3.56 & 3.59 \\
0.97 & 6.69 & 9.17 \\
0.90 & 9.49 & 13.71 \\
0.84 & 20.96 & 25.97 \\
\hline
\end{tabular}

The specific test steps are as follows:

(1) Soil Preparation. The preparation of remolded soil had the steps similar to the SWCC test. For the homogenization 


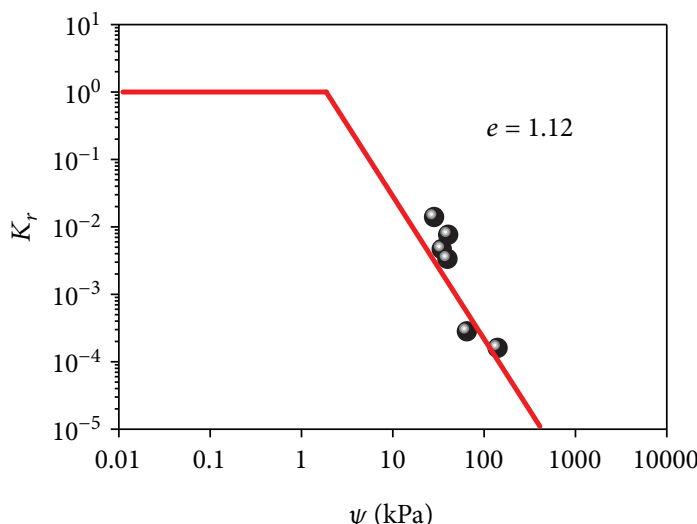

- Experimental data - Model prediction

(a)

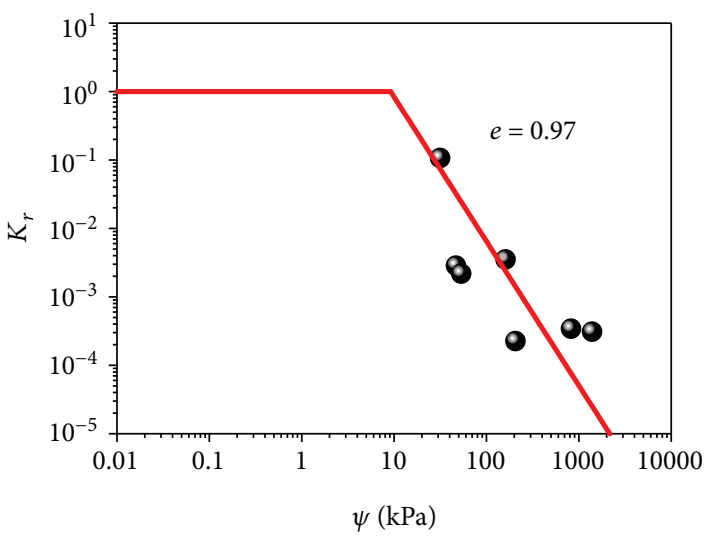

Experimental data Model prediction

(c)

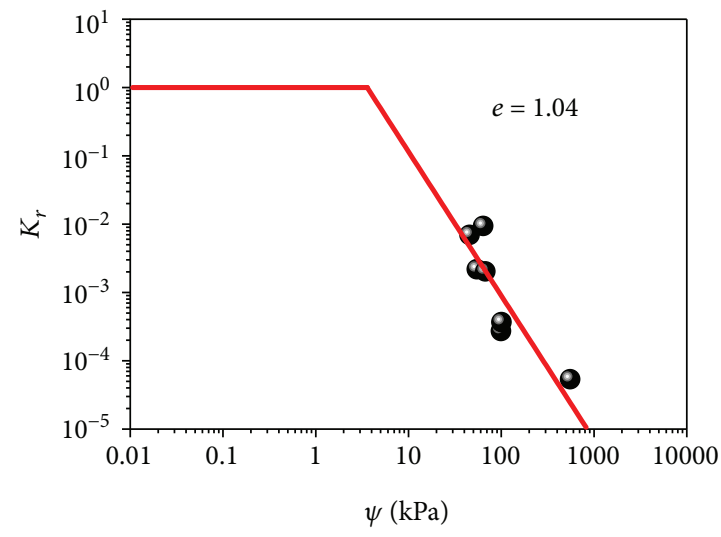

- Experimental data Model prediction

(b)

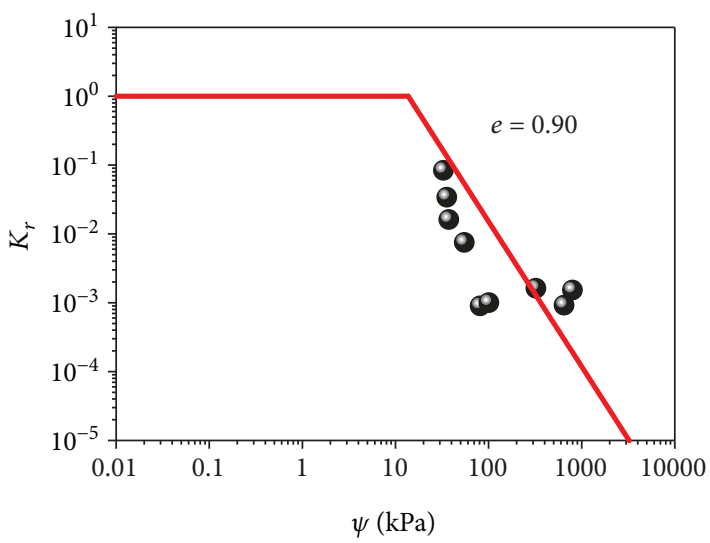

- Experimental data Model prediction

(d)

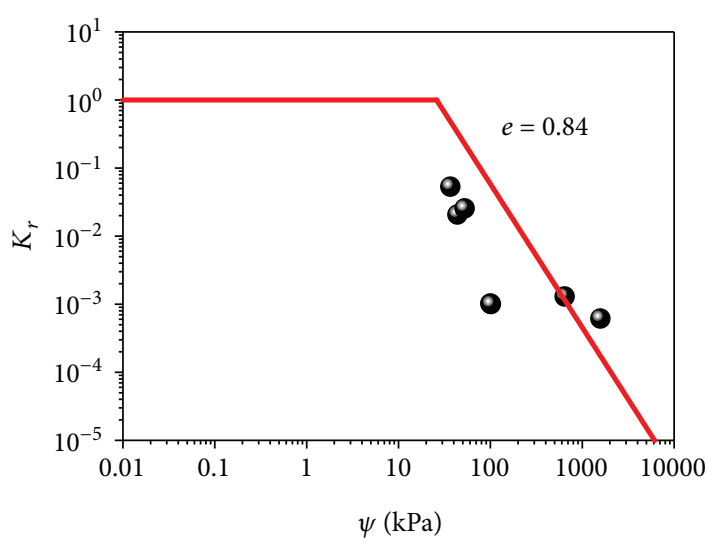

- Experimental data Model prediction

(e)

FIGURE 7: Comparison between predicted values and experimental results of the relative hydraulic conductivity of deformable Hunan clay.

of water, the soil sample was stirred evenly by the blender, and then, the soil was sealed for more than 48 hours. After the water migrate uniformly, the gravimetric water content was measured again.
(2) Sample Preparation. The sample was prepared by stratified compaction. To ensure close contact between soil layers, the interface of different layers was scraped. When the sample preparation was finished, an $8 \mathrm{~cm}$ thick fine sand 
layer was evenly spread on the surface of each sample, which ensured that the water permeated uniformly and prevented the surface layer of each sample from caking during the seepage process.

(3) Water Permeation. The certain amount of water $(1500 \mathrm{~mL})$ was continuously added on the top of the sample during the $20 \mathrm{~min}$. Then, it is necessary to immediately seal the top of the cylinder with fresh film to prevent water evaporation.

(4) Measurement of Gravimetric Water Content. Taking a soil sample for instance, when the wetting front infiltrated in the heights of $15 \mathrm{~cm} \sim 20 \mathrm{~cm}$ of the soil sample, the gravimetric water content from top to bottom was beginning to be measured by taking out a certain amount of soil from a column of holes at the same time. By repeating the above work, the gravimetric water content of the other columns was measured at different time intervals, which depends on the falling velocity of wetting front. Finally, the variation of gravimetric water content with heights of soil samples at different times can be obtained.

The soil samples at initial void ratios of 1.12, 1.04, $0.97,0.90$, and 0.84 were tested in turn by using the above method. The unsaturated hydraulic conductivity was calculated using the method presented by Wang et al. [56]. Based on the experimental saturated hydraulic conductivity, the unsaturated hydraulic conductivity is converted to the relative hydraulic conductivity (Figure 4). It is noteworthy that the calculated relative hydraulic conductivity of Hunan clay is based on capillary theory, so the matric suction considered in this paper is mainly influenced by capillary water. However, at the stage of higher matric suction (about greater than $1000 \mathrm{kPa}$ ), the matric suction is greatly influenced by film water which is not studied in this paper, so the corresponding data are not analyzed. That is to say, the proposed model is suitable for lower suction (about smaller than $1000 \mathrm{kPa}$ ) stage because capillary suction is only considered.

2.7. Model Verification. By fitting equation (11) to the experimental SWCC at a reference state $\left(e_{0}=1.12\right)$, the fractal dimension $(D)$ was determined to be 2.892 for deformable Hunan clay (Figure 5). While by fitting equation (6) to the experimental SWCC at a reference state $\left(e_{0}=1.12\right)$, the corresponding air-entry value $\psi_{a 0}$ can be determined to be 1.81 (Figure 6). According to equation (6), the volumetric water content is a constant $\left(\theta_{s}\right)$ when the range of matric suction is $\psi<\psi_{a}$ (it can be represented as AB in Figure 6).

On the basis of the fractal dimension and air-entry value at a reference state, the air-entry values of Hunan clay at deformed state were determined using Equation (12), as shown in Table 2. It can be seen that the predicted airentry values are close to the experimental results at a deformed state.

Based on the fractal dimension and the predicted airentry values at a deformed state, the relative hydraulic conductivity of Hunan clay at a deformed state can be calculated by using equation (9). In Figure 7, the predicted values are in good agreement with the measured values, which verifies the accuracy of the proposed method.

\section{Conclusions}

A fractal prediction method was presented to determine the relative hydraulic conductivity under deformation condition in this study. The method was only necessary to obtain the fractal dimension and the air-entry value at a reference state by the SWCC test. The relative hydraulic conductivity at a deformed state was predicted combined with the air-entry value and fractal form of the hydraulic conductivity model. Compared with the tedious calculation work (i.e., integral and sectional calculation) in the existing procedure, the proposed method requires less work to determine the relative hydraulic conductivity under deformation condition. In order to demonstrate the accuracy of the proposed method, the instantaneous profile method of deformable Hunan clay was carried out to obtain the experimental data of the relative hydraulic conductivity with different initial void ratios. By comparing the measured values with the predicted values, the accuracy of the proposed method was validated.

\section{Data Availability}

The SWCC and hydraulic conductivity data of Hunan clay used to support the findings of this study are included within the article.

\section{Conflicts of Interest}

The authors declare no conflict of interest.

\section{Authors' Contributions}

G.T., H.X., and X.Z. conceived and performed the experiments and wrote the manuscript. J.C., Q.C., and Y.C. performed the data analysis and revised the manuscript.

\section{Acknowledgments}

The research was funded by the National Key R\&D Program of China (No. 2016YFC0502208), National Natural Science Foundation of China (No. 41722403), Outstanding Young and MiddleAged Scientific and Technological Innovation Team Project of Hubei Provincial Department of Education (T201605), and Research Project of Hubei Provincial Department of Education (No. D20161405), and they are gratefully acknowledged.

\section{References}

[1] J. H. Dane and G. C. Topp, Methods of Soil Analysis: Part 4 Physical Methods, Soil Science Society of America, 2002.

[2] A. Klute, "Laboratory measurement of hydraulic conductivity of unsaturated soils," in Methods of Soil Analysis, Monograph 9, Part 1, pp. 253-261, American Society of Agronomy, 1965.

[3] P. A. Londra, "Simultaneous determination of water retention curve and unsaturated hydraulic conductivity of substrates using a steady-state laboratory method," HortScience, vol. 45, no. 7, pp. 1106-1112, 2010. 
[4] C. Gallage, J. Kodikara, and T. Uchimura, "Laboratory measurement of hydraulic conductivity functions of two unsaturated sandy soils during drying and wetting processes," Soils and Foundations, vol. 53, no. 3, pp. 417-430, 2013.

[5] S. J. Richards and L. V. Weeks, "Capillary conductivity values from moisture yield and tension measurements on soil columns," Soil Science Society of America Journal, vol. 17, no. 3, pp. 206-209, 1953.

[6] H. Krisdani, H. Rahardjo, and E.-C. Leong, "Use of instantaneous profile and statistical methods to determine permeability functions of unsaturated soils," Canadian Geotechnical Journal, vol. 46, no. 7, pp. 869-874, 2009.

[7] A. K. Leung, J. L. Coo, C. W. W. Ng, and R. Chen, "New transient method for determining soil hydraulic conductivity function," Canadian Geotechnical Journal, vol. 53, no. 8, pp. 1332-1345, 2016.

[8] J. Cai, E. Perfect, C.-L. Cheng, and X. Hu, "Generalized modeling of spontaneous imbibition based on Hagen-Poiseuille flow in tortuous capillaries with variably shaped apertures," Langmuir, vol. 30, no. 18, pp. 5142-5151, 2014.

[9] Y. Mualem, "Hydraulic conductivity of unsaturated porous media: generalized macroscopic approach," Water Resources Research, vol. 14, no. 2, pp. 325-334, 1978.

[10] E. C. Leong and H. Rahardjo, "Permeability functions for unsaturated soils," Journal of Geotechnical and Geoenvironmental Engineering, vol. 123, no. 12, pp. 1118-1126, 1997.

[11] Y. Mualem and A. Klute, Hydraulic Conductivity of Unsaturated Soils: Prediction and Formulas, American Society of Agronomy, 1986.

[12] S. F. Averjanov, "About permeability of subsurface soils in case of incomplete saturation," Engineering Collection, vol. 7, pp. 19-21, 1950.

[13] W. R. Gardner, "Some steady-state solutions of the unsaturated moisture flow equation with application to evaporation from a water table," Soil Science, vol. 85, no. 4, pp. 228232, 1958.

[14] R. H. Brooks and A. T. Corey, "Hydraulic properties of porous media," Hydrology, vol. 3, no. 1, pp. 352-366, 1964.

[15] J. M. Davidson, L. R. Stone, D. R. Nielsen, and M. E. Larue, "Field measurement and use of soil-water properties," Water Resources Research, vol. 5, no. 6, pp. 1312-1321, 1969.

[16] J. D. Campbell, Pore pressures and volume changes in unsaturated soils, [Ph.D. thesis], University Illinois Urbana Champaign, 1973.

[17] D. G. Fredlund, A. Xing, and S. Huang, "Predicting the permeability function for unsaturated soils using the soilwater characteristic curve," Canadian Geotechnical Journal, vol. 31, no. 4, pp. 533-546, 1994.

[18] S. S. Agus, E. C. Leong, and T. Schanz, "Assessment of statistical models for indirect determination of permeability functions from soil-water characteristic curves," Géotechnique, vol. 53, no. 2, pp. 279-282, 2003.

[19] E. C. Childs and N. Collis-George, "The permeability of porous materials," Proceedings of the Royal Society A, vol. 201, no. 1066, pp. 392-405, 1950.

[20] N. Collis-George, "Calculation of the permeability of porous media from their moisture characteristics," Transactions, American Geophysical Union, vol. 34, no. 4, pp. 589-593, 1953.

[21] N. T. Burdine, "Relative permeability calculations from pore size distribution data," Journal of Petroleum Technology, vol. 5, no. 3, pp. 71-78, 1953.
[22] Y. Mualem, "A new model for predicting the hydraulic conductivity of unsaturated porous media," Water Resources Research, vol. 12, no. 3, pp. 513-522, 1976.

[23] M. T. van Genuchten, "A closed-form equation for predicting the hydraulic conductivity of unsaturated soils," Soil Science Society of America Journal, vol. 44, no. 5, pp. 892-898, 1980.

[24] R. J. Kunze, G. Uehara, and K. Graham, "Factors important in the calculation of hydraulic conductivity," Soil Science Society of America Journal, vol. 32, no. 6, pp. 760-765, 1968.

[25] S. Oh, Y. Kim, and J.-W. Kim, "A modified van GenuchtenMualem model of hydraulic conductivity in Korean residual soils," Water, vol. 7, no. 10, pp. 5487-5502, 2015.

[26] V. V. Terleev, W. Mirschel, V. L. Badenko, and I. Y. Guseva, "An improved Mualem-Van Genuchten method and its verification using data on Beit Netofa clay," Eurasian Soil Science, vol. 50, no. 4, pp. 445-455, 2017.

[27] B. B. Mandelbrot and J. A. Wheeler, "The fractal geometry of nature," American Journal of Physics, vol. 51, no. 3, pp. 286287, 1983.

[28] J. Cai, X. Hu, B. Xiao, Y. Zhou, and W. Wei, "Recent developments on fractal-based approaches to nanofluids and nanoparticle aggregation," International Journal of Heat and Mass Transfer, vol. 105, pp. 623-637, 2017.

[29] J. Cai, L. Zhang, Y. Ju, G. Pia, and Z. Zhang, “An introduction to fractal-based approaches in unconventional reservoirs-part I," Fractals, vol. 26, no. 2, article 1802001, 2018.

[30] Y. Xu, "Shear strength of granular materials based on fractal fragmentation of particles," Powder Technology, vol. 333, pp. 1-8, 2018.

[31] E. Perfect, M. Díaz-Zorita, and J. H. Grove, "A prefractal model for predicting soil fragment mass-size distributions," Soil and Tillage Research, vol. 64, no. 1-2, pp. 79-90, 2002.

[32] L. Zhang, X. Zhang, H. Chai, Y. Li, and Y. Zhou, "Pore structure characterization for a continental lacustrine shale parasequence based on fractal theory," Fractals, vol. 27, no. 1, article 1940006, 2019.

[33] Y. Xu and Y. Wang, "Size effect on specific energy distribution in particle comminution," Fractals, vol. 25, no. 2, article 1750016, 2017.

[34] S. W. Tyler and S. W. Wheatcraft, "Fractal processes in soil water retention," Water Resources Research, vol. 26, no. 5, pp. 1047-1054, 1990.

[35] P. Xu, H. Liu, A. P. Sasmito, S. Qiu, and C. Li, "Effective permeability of fractured porous media with fractal dualporosity model," Fractals, vol. 25, no. 4, article 1740014, 2017.

[36] A. Cihan, J. S. Tyner, and E. Perfect, "Predicting relative permeability from water retention: a direct approach based on fractal geometry," Water Resources Research, vol. 45, no. 4, 2009.

[37] Y. F. Xu and D.'. A. Sun, "A fractal model for soil pores and its application to determination of water permeability," Physica A: Statistical Mechanics and its Applications, vol. 316, no. 1-4, pp. 56-64, 2002.

[38] Y. Xu, "Calculation of unsaturated hydraulic conductivity using a fractal model for the pore-size distribution," Computers and Geotechnics, vol. 31, no. 7, pp. 549-557, 2004.

[39] D. S. Sun, P. Liu, X. H. Xia, and J. H. Wang, "Permeability coefficient of unsaturated soils," Journal of Hydraulic Engineering, vol. 35 , no. 3 , pp. 71-75, 2004. 
[40] B. Ghanbarian-Alavijeh and A. G. Hunt, "Unsaturated hydraulic conductivity in porous media: percolation theory," Geoderma, vol. 187-188, pp. 77-84, 2012.

[41] A. G. Hunt, B. Ghanbarian, and K. C. Saville, "Unsaturated hydraulic conductivity modeling for porous media with two fractal regimes," Geoderma, vol. 207-208, pp. 268-278, 2013.

[42] S. D. Bartolo, C. Fallico, G. Severino, and M. Veltri, "Two fractal regimes of the soil hydraulic properties," Applied Mathematics, vol. 5, no. 12, pp. 1773-1779, 2014.

[43] M. A. Alfaro Soto, H. K. Chang, and M. T. van Genuchten, "Fractal-based models for the unsaturated soil hydraulic functions," Geoderma, vol. 306, pp. 144-151, 2017.

[44] A. Lloret and E. E. Alonso, "Consolidation of unsaturated soils including swelling and collapse behaviour," Géotechnique, vol. 30, no. 4, pp. 449-477, 1980.

[45] S. Huang, S. L. Barbour, and D. G. Fredlund, "Development and verification of a coefficient of permeability function for a deformable unsaturated soil," Canadian Geotechnical Journal, vol. 35, no. 3, pp. 411-425, 1998.

[46] S. Huang, D. G. Fredlund, and S. L. Barbour, "Measurement of the coefficient of permeability for a deformable unsaturated soil using a triaxial permeameter," Canadian Geotechnical Journal, vol. 35, no. 3, pp. 426-432, 1998.

[47] T. H. Wang, J. Lu, and J. F. Zhang, "Experimental study on permeability coefficient of artificially compacted unsaturated loess considering influence of density," Chinese Journal of Rock Mechanics and Engineering, vol. 25, no. 11, pp. 23642368, 2006.

[48] S. Assouline, "Modeling the relationship between soil bulk density and the hydraulic conductivity function," Vadose Zone Journal, vol. 5, no. 2, pp. 697-705, 2006.

[49] R. Hu, Y.-F. Chen, H.-H. Liu, and C.-B. Zhou, "A water retention curve and unsaturated hydraulic conductivity model for deformable soils: consideration of the change in pore-size distribution," Géotechnique, vol. 63, no. 16, pp. 1389-1405, 2013.

[50] G. Cai, A. Zhou, and D. Sheng, "Permeability function for unsaturated soils with different initial densities," Canadian Geotechnical Journal, vol. 51, no. 12, pp. 1456-1467, 2014.

[51] A. Zhou, Y. Fan, W.-C. Cheng, and J. Zhang, "A fractal model to interpret porosity-dependent hydraulic properties for unsaturated soils," Advances in Civil Engineering, vol. 2019, Article ID 3965803, 13 pages, 2019.

[52] G. L. Tao and L. W. Kong, "A model for determining the permeability coefficient of saturated and unsaturated soils based on micro pore channel and its application," Journal of Hydraulic Engineering, vol. 48, no. 6, pp. 702-709, 2017.

[53] G. Tao, Y. Chen, L. Kong, H. Xiao, Q. Chen, and Y. Xia, “A simple fractal-based model for soil-water characteristic curves incorporating effects of initial void ratios," Energies, vol. 11, no. 6, p. 1419, 2018.

[54] G. L. Tao, X. K. Wu, H. L. Xiao, Q. Chen, and J. Cai, “A unified fractal model for permeability coefficient of unsaturated soil," Fractals, vol. 27, no. 1, article 1940012, 2019.

[55] G. L. Tao, L. W. Kong, H. L. Xiao, Q. Ma, and Z. Z. Zhu, "Fractal characteristics and fitting analysis of soil-water characteristic curves," Rock \& Soil Mechanics, vol. 35, no. 9, pp. 24432447, 2014.

[56] H. Wang, T. L. Li, and Y. K. Fu, "Determining permeability function of unsaturated loess by using instantaneous profile method," Journal of Hydraulic Engineering, vol. 45, no. 8, pp. 997-1003, 2014. 

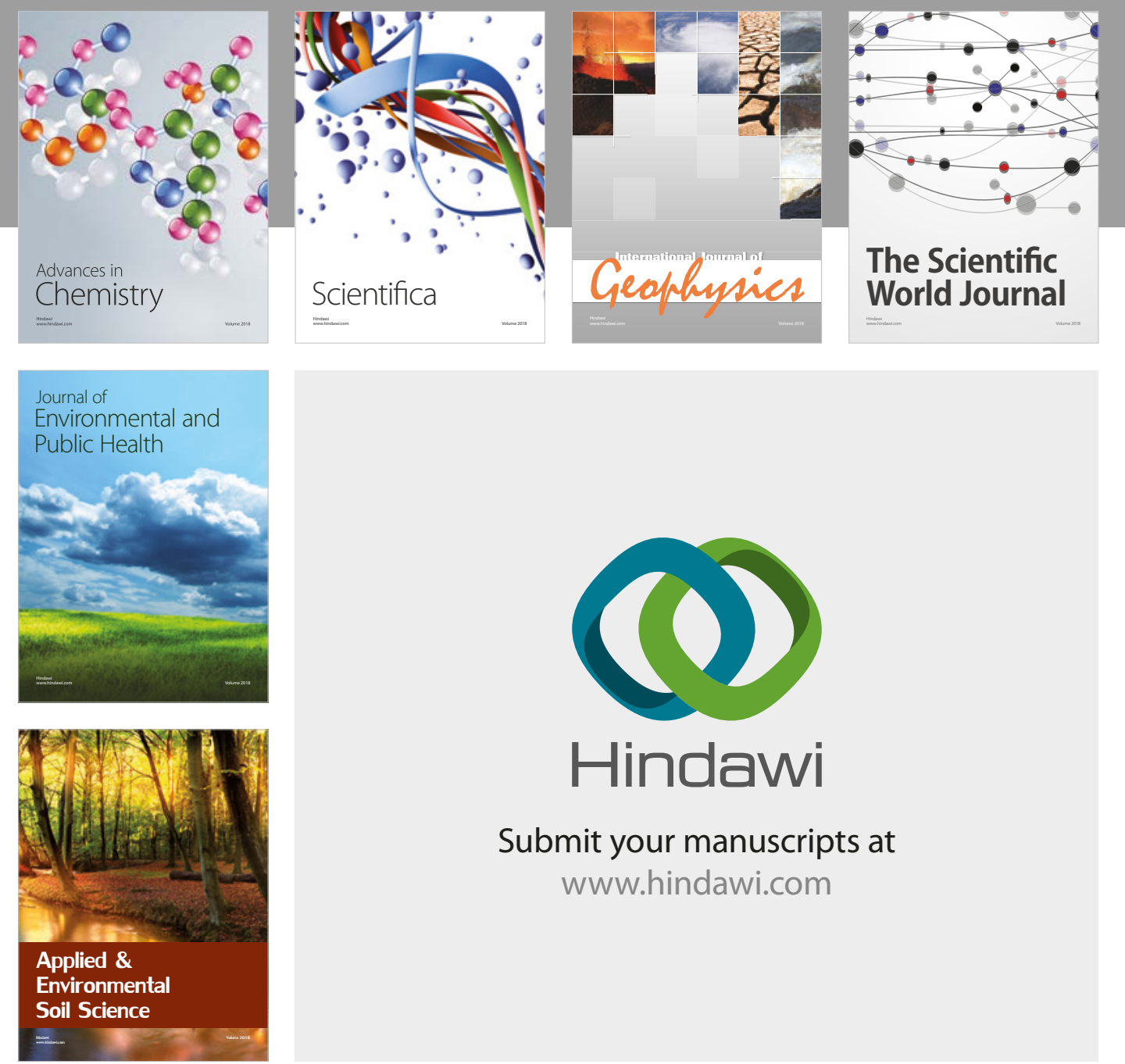

The Scientific

\section{World Journal}
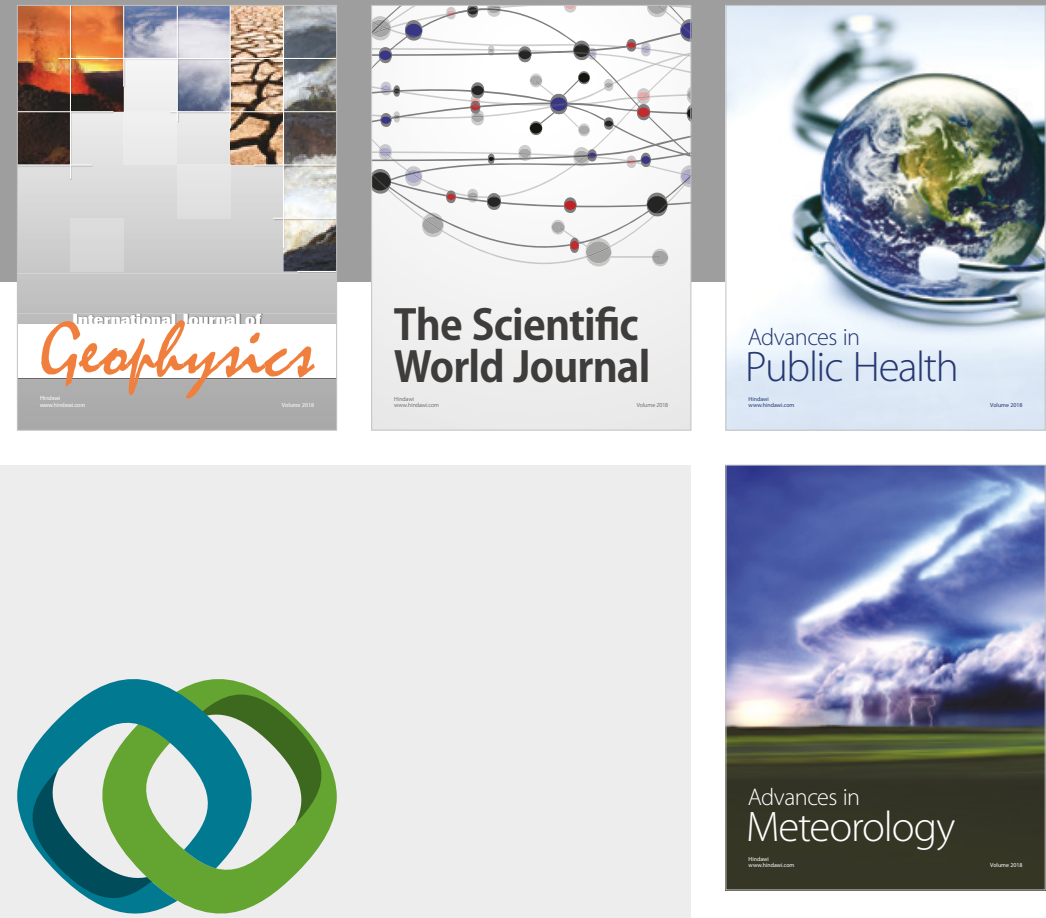

Advan

Public Health

\section{Hindawi}

Submit your manuscripts at

www.hindawi.com
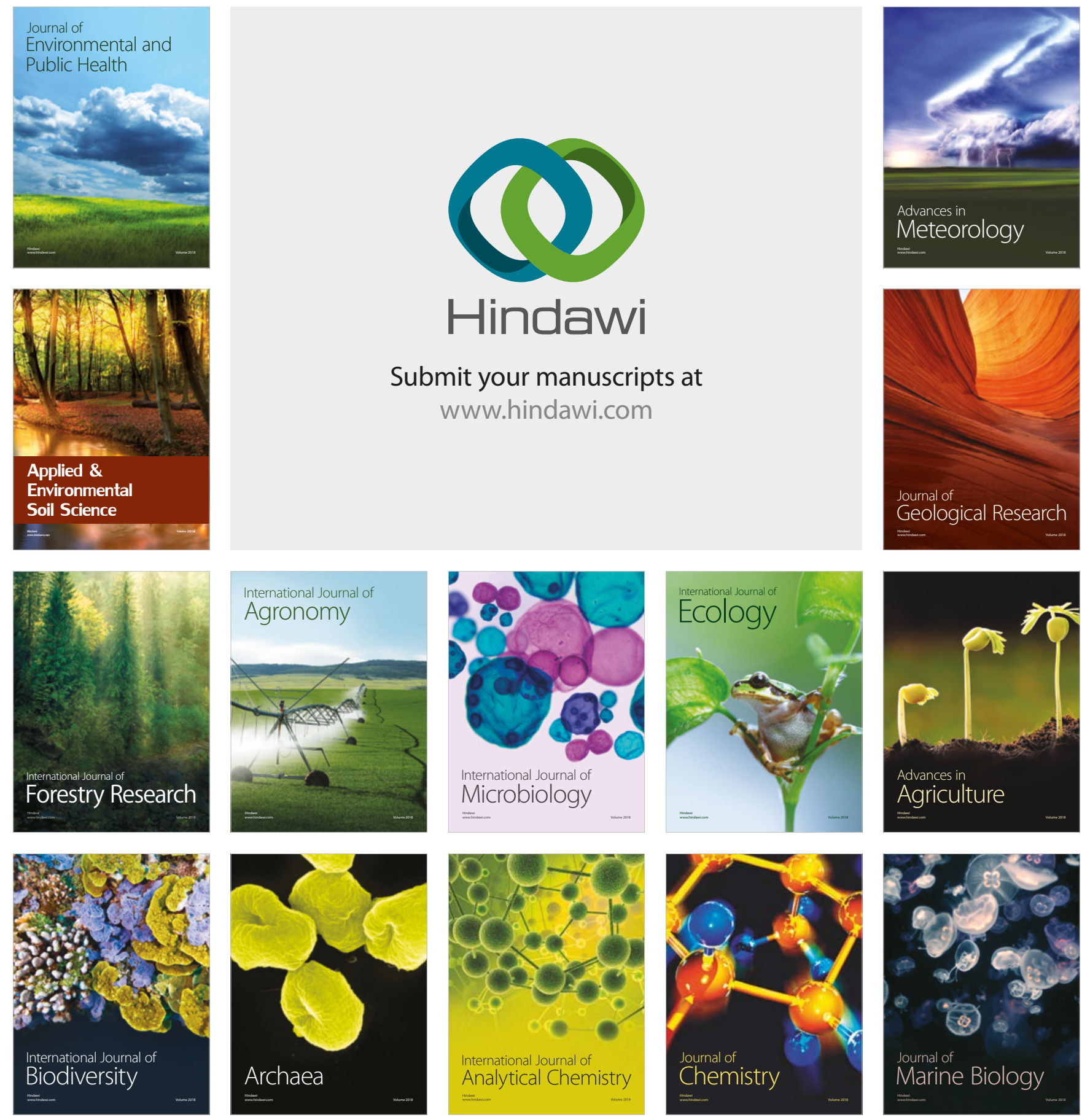